\title{
Editorial
}

Pensar en Movimiento:

Revista de Ciencias del Ejercicio y la Salud ISSN 1659-4436

Vol. 16, No.1, pp. 1 - 4

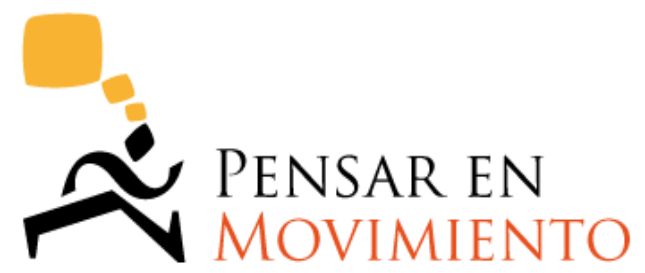

REVISTA DE CIENCIAS DEL EJERCICIO Y LA SALUD

Abre el $1^{\circ}$ de enero, cierre al 30 de junio, 2018

\section{LA PUBLICACIÓN CONTINUA Y LA PUBLICACIÓN PRELIMINAR: MODALIDADES DE PUBLICACIÓN ELECTRÓNICA EN PENSAR EN MOVIMIENTO}

\author{
Fabiola Quirós-Segura, Licda. \\ Editora de Pensar en Movimiento: \\ Revista de Ciencias del Ejercicio y la Salud
}

Publicado: 2018-06-12

El paso de la publicación de revistas del formato impreso al formato electrónico supuso una serie esfuerzos adicionales para los directores y editores de revistas científicas, quienes estaban acostumbrados a las características del formato impreso, en el que la revista se publicaba una vez que todos los artículos que componían el número o fascículo habían finalizado el proceso editorial. Dicha práctica fue trasladada a la versión electrónica en sus inicios, ya que era usual que se colgara una copia de la versión impresa en los sitios web de diversas revistas.

Pese a que en principio hubo mucha resistencia a la utilización de revistas electrónicas e inclusive se llegó a cuestionar la legitimidad de las mismas, con el paso del tiempo fueron evidentes las ventajas que dicho formato de publicación presentaba con respecto al impreso. Esto debido a que la publicación de artículos a texto completo en formato electrónico contribuye a mejorar su difusión, divulgación e impacto, ya que, al colocarse en línea, se disminuye considerablemente el tiempo en que los lectores acceden al conocimiento, lo que contribuye a aumentar el índice de citación de las publicaciones. Además, debe tomarse en consideración que al formato electrónico de publicación pueden incorporársele otros recursos digitales que no pueden ser agregados al impreso, tal es el caso de videos y audios, entre otros (Travieso, 2003; Abadal y Rius, 2006). 
Es así como los sitios web de las revistas se convierten en el elemento de mayor importancia. En algunos casos, las revistas impresas han dejado el formato impreso y han optado por publicar únicamente su versión electrónica e, inclusive, la tendencia es que las revistas desde su nacimiento sean únicamente electrónicas (Pérez, 2015).

La publicación de revistas en formato electrónico no solo supuso un cambio en la forma en que se publican los artículos, sino que, además, su puesta en marcha dio pie a la creación de alternativas de publicación, que favorecen la rapidez con que los nuevos hallazgos científicos son puestos en línea para ser consultados por los lectores, tal es el caso de la publicación continuada y la publicación preliminar. Dichas alternativas de publicación coexisten y retroalimentan la publicación electrónica, mientras que coadyuvan a reducir los tiempos de publicación de las revistas científicas, sin sacrificar la calidad con que son procesados los artículos sometidos a evaluación.

Pensar en Movimiento se suma a la publicación electrónica en el año 2009 y es a partir de entonces que se decide hacer uso de la publicación continuada, dicha alternativa de publicación consiste en colgar el artículo en la página web de la revista en el momento en que este se encuentra listo para publicación, sin que los demás artículos que componen el fascículo se encuentren listos para ser publicados. Es decir, los artículos son colgados uno a uno en la página de la revista, una vez que estos han culminado el proceso de revisión por pares, el proceso de corrección de originales, la corrección filológica, la traducción y la maquetación.

Si bien, según Pérez (2015), la implementación de la publicación continuada podría llegar a eliminar la periodicidad, existe el caso de revistas que deciden mantener sus periodos regulares de cierre, mientras que utilizan dicha modalidad de publicación. Este es el caso de Pensar en Movimiento, pues pese a utilizar la publicación continuada, mantiene sus cierres semestrales, lo que permite alimentar progresivamente los dos números publicados por la revista, hasta donde el periodo de cierre de cada uno de los números lo permita.

Al respecto de la publicación preliminar o anticipada, Pensar en Movimiento comienza con su implementación a mediados del 2014, adaptando las características originales de los preprints a la lógica de publicación de una revista científica. Para entender las adaptaciones realizadas al preprint, debe entenderse primero cómo funciona este. Según Spinack (2016), el preprint es una versión preliminar de un artículo, que es depositada por los autores en repositorios en los que diversos investigadores hacen observaciones y sugerencias al documento, para que este pueda ser mejorado por los autores, antes de que estos decidan enviarlo formalmente a un proceso de revisión en una revista científica; siendo así, lo que se lleva a escrutinio no es la versión final del documento, sino una versión que es mejorada después del proceso de revisión que se realiza por diversos investigadores en los repositorios preprint y es precisamente el documento mejorado el que es enviado a un proceso formal de revisión.

Lo anterior no podría adecuarse tal cual a la lógica de una revista científica, en la que se someten a escrutinio manuscritos en su versión final, por lo que se decide implementar el preprint desde otra perspectiva, en la que los artículos son subidos a la 
página web de Pensar en Movimiento una vez que estos han sido aceptados para publicación (cuando los autores han integrado satisfactoriamente al manuscrito todas las correcciones sugeridas por los revisores). A esta modalidad la hemos llamado "recién horneado", lo que muchas revistas de primer orden en inglés llaman "Published ahead of print' y que en este editorial se ha llamado "publicación preliminar".

Para llegar a esa etapa, los artículos deben haber superado: la etapa de revisión preliminar por parte del editor asociado a cargo, la revisión de plagio, una primera ronda de revisión filológica, la revisión por pares, la etapa de corrección del manuscrito por parte de los autores, el envío a los revisores de las correcciones realizadas por los autores (en caso de que estos lo hubiesen solicitado), la aceptación del manuscrito por parte del editor y la revisión de citas y referencias dentro del texto.

Una vez concluidas las etapas mencionadas, se prepara la publicación preliminar (o manuscrito "recién horneado"), que será subido a la página web de Pensar en Movimiento. Esta versión del artículo se acompaña de un cintillo en el que se indica que la versión publicada no es la versión final del documento y puede sufrir algunas modificaciones una vez que emprenda el proceso de maquetación y traducción. En la carta de originalidad y licencia de derechos utilizada por nuestra revista se le da la opción al autor de elegir si desea o no que su artículo sea publicado de forma anticipada.

Para Pensar en Movimiento, la implementación de la publicación continuada y la publicación de artículos en versión "recién horneado" ha significado una disminución considerable en los tiempos de publicación, que ha permitido poner en línea lo antes posible los artículos aceptados para publicación. Lo anterior, en conjunto con otras prácticas editoriales, ha traído consigo un aumento sostenido en la consulta, descarga y visualización de los artículos publicados.

Asimismo, la puesta en marcha de ambas alternativas de publicación ha favorecido de manera continua el proceso editorial de Pensar en Movimiento, pues para que ambos modelos funcionen de forma óptima ha sido necesario examinar con cuidado todos los pasos que forman parte de la publicación de un artículo científico, lo que ha permitido identificar los puntos endebles que deben ser mejorados.

Sumado a lo anterior, la implementación del "recién horneado" trajo consigo un conocimiento más amplio de la plataforma Open Journals System (OJS), ya que si se sigue el flujo que este sistema propone para la publicación de manuscritos, no es posible publicar en versión preliminar, sino únicamente la versión final del manuscrito, por lo que fue necesario buscar la forma de poder utilizar dicha alternativa dentro de las reglas del OJS.

Pese a las resistencias que presentan ambos modelos, debido a los cambios que podría significar su implementación con respecto al proceso en la gestión editorial que posee una revista y a la modificación que esta podría sufrir en los periodos de recepción de artículos (esto si así lo decidiera su Comité Editorial), no puede negarse que tanto la publicación continuada como la preliminar disminuyen los tiempos de publicación de los artículos, sin que esto implique que se está disminuyendo la calidad de ninguna de las fases del proceso editorial que estos emprenden en el flujo de publicación, ya que, como se mencionó en párrafos anteriores, se encuentra establecido claramente el proceso que - 3 -

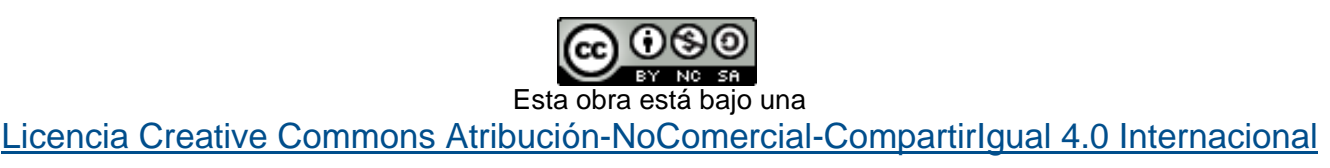


deben emprender los manuscritos antes de ser colgados en la página web de la revista. Adicionalmente, al colgarse el artículo en línea lo antes posible, se aumenta la difusión de las publicaciones y, por ende, su impacto.

Cualquiera de las dos alternativas puede ser implementada de forma individual (utilizando únicamente una de ellas) o en conjunto (utilizando ambas alternativas al mismo tiempo, como lo hace Pensar en Movimiento desde hace varios años). Su utilización debe adecuarse al área disciplinar en la que se encuentre circunscrita una revista, pues eso puede influir e, inclusive, determinar si se pueden o no utilizar la publicación continuada y la publicación preliminar.

\section{REFERENCIAS}

Abadal, E. y Rius, LI. (2006). Revistas científicas digitales: características e indicadores. Revista de Universidad y Sociedad del Conocimiento, 3(1), 0. Recuperado de http://www.redalyc.org/html/780/78030109/

Pérez, A. (2015). La publicación continuada frente a la publicación periódica. Otra vuelta de tuerca en la edición de revistas científicas. Revista Española de Salud Pública, 89(6), 533-536. Recuperado de http://dx.doi.org/10.4321/S1135-57272015 $\underline{000600001}$

Spinak, E. (22 de noviembre del 2016). ¿Qué es este asunto de los preprint? Scielo en Perspectiva. Recuperado de https://blog.scielo.org/es/2016/11/22/que-es-esteasunto-de-los-preprints/\#.WuCWXy5ubX4

Travieso, M. (2003). Las publicaciones electrónicas: una revolución en el siglo XXI. ACIMED, 11(2), 1-2. Recuperado de http://scielo.sld.cu/scielo.php?script=sci arttext\&pid=S1024-94352003000200001 